\title{
An electron microscopic study of hypertrophic neuropathy of Dejerine and Sottas
}

\author{
R. O. WELLER \\ From the Department of Pathology, Guy's Hospital Medical School, London
}

Hypertrophic peripheral neuropathy was first recorded in a patient aged 58 years by Gombault and Mallet in 1889, as a case of tabes beginning in childhood. The disease was further described by Dejerine and Sottas (1893), in a brother and sister, as progressive hypertrophic interstitial neuritis of infancy. The cases reported since that time, and well reviewed by Austin (1956), have shown considerable variation clinically. The age of onset of the disease varies widely, and symptoms may not develop until middle age; the disease often, but not always, occurs in more than one member of the same family. There is such a wide range of symptoms associated with the disease that Russell and Garland (1930) suggested that enlargement of nerves and wasting of muscles are the only constant clinical features. Commonly, however, there is a clinical picture of chronic progressive peripheral sensory and motor neuropathy with weakness, muscle wasting in the limbs, and glove and stocking sensory changes (Austin, 1956). This clinical picture is accompanied by distinctive thickening of nerves that show loss of myelin, cellular hyperplasia, and the formation of whorls of cells around the remaining nerve fibres (Dejerine and Sottas, 1893). There is a definite family history in many cases, as in the brother and sister originally described by Dejerine and Sottas (1893) and later by Dejerine and André-Thomas (1906), but sporadic cases do occur.

The three cases described in this paper represent, perhaps, the three major groups of patients suffering from this disease complex. The first, a young child, had been severely affected from birth and had no definite family history; the second, a man of 61 years, again with no family history, suffered from an acute fulminating type of the disease with a short clinical course and rapid progression. The third case was a truly familial type similar to that described by Dejerine and Sottas. The disease occurred in late childhood, was slowly progressive, and the patient had a sister similarly affected.

Examination of the sural nerves from these three patients with the electron microscope has made it possible accurately to identify the hyperplastic elements within the whorls and to disclose the true state of the persisting nerve fibres and their myelin sheaths.

\section{CASE HISTORIES}

CASE 1 G.H. (no. 179060) is a 6-year-eld girl who had a normal birth (20 February 1960) and post-natal period but thereafter failed to develop according to the normal milestones. She smiled at 6 weeks, but she could not lift her head from the prone position until 8 months. At 10 months she was able to roll over and by 20 months was sitting unsupported. The patient was able to pull herself into a standing position at 2 years and remain standing if supported. Intellectually, she seemed to develop normally.

In June 1963 the patient, then aged 3 years 3 months, was admitted to Guy's Hospital under Dr. P. R. Evans for investigation.

On examination, she was an intelligent, bright, child, who spoke well and counted up to 10 . She was able to feed herself slowly with a spoon but could not walk. No abnormality was found except in the nervous system. The cranial nerves were normal, but there was otherwise a generalized hypotonia. Tendon reflexes were reduced in the arms and absent in the legs. Plantar responses were flexor. There was slight weakness in the arms and hands, and she had difficulty in manipulative movements. Flexion at both knees was weak and abduction of both hips was very weak. There was some muscle wasting in the lower limbs and buttocks. Passive movements were full and no sensory loss was detected.

She had a pyrexial illness, when aged 1 year, which was diagnosed as a virus infection and measles in December 1964.

The mother had a normal pregnancy. An episiotomy was performed during the second stage of labour and the child cried immediately after birth. She was breast fed for 3 months.

Family history The patient's mother was well and the nerve conduction time in the right lateral popliteal nerve $(48 \mathrm{~m}$./sec.) was within normal limits (Dr. R. G. Willison). The mother had a brother who was said to have been 'floppy', to have had a hare lip, and to have died with pneumonia at 8 months. The patient's father was well and the nerve conduction time in the right lateral popliteal nerve $(50 \mathrm{~m}$. $/ \mathrm{sec}$.) was within normal limits (Dr. R. G. Willison). The patient's one brother and two sisters 
appeared to be normal though no nerve conduction studies were performed upon them.

Investigations On 16 April 1964 nerve conduction studies of the right median nerve (Dr. R. G. Willison) showed a high stimulus threshold and very slow conduction times. Accurate measurements were difficult as adequate stimuli were very painful.

A muscle biopsy (Dr. J. B. Cavanagh) on 7 June 1963 showed no denervation atrophy but marked loss of myelin in the intramuscular nerves without reduction in the number of axons. There was concentric cellular hyperplasia within the nerves and the diagnosis of hypertrophic neuropathy was made. A radiograph of the spine was normal.

Progress Early in 1964 the patient had a marked kyphosis and progressed in a series of 'rabbit hops' supporting herself on her hands and knees with her legs splayed; she frequently fell forward onto her face while hopping. Callipers were then fitted to both legs and she was able to retain an upright posture. By February 1965 she was able to ride a tricycle and pedal it on flat ground; she started school in September of that year. She is now (August 1966) able to walk without her callipers and supported only by a child of her own age.

The sural nerve biopsy was taken in January, 1966.

CASE 2 G.H. (no. A.270958), a man of 60 years, developed a course tremor of both hands in April 1965, which gradually became worse and later involved his legs. In June 1965 the patient experienced soreness in the right heel and then pain spreading to involve both feet and legs to the level of the knees by October 1965 . Gradually his legs became weak, and he noticed some loss of power in the arms and hands. He had no sensory symptoms in the upper limbs. During the first four months of his illness the patient's appetite was very poor and he lost weight, but during the six months before admission to Guy's Hospital he had regained 2 stone. He was admitted to Guy's hospital under Dr. M. J. McArdle in May 1966.

On examination, the patient was not anaemic and there was no clubbing of the fingers. No abnormality was found in the cranial nerves. There was a marked rhythmic, pronation-supernation, intention tremor in both upper limbs with moderate weakness of all muscle groups and wasting of the small muscles of the hands. The patient had a rhythmic postural tremor of both legs with severe ataxia, and marked muscle weakness. The reflexes were all reduced, and no ankle jerks or plantar responses could be elicited. There was loss of all sensation below the mid-thigh region with impaired joint position sense. Sensation was also lost in the arms but with some retention of pain sensibility. Examination of other systems showed no abnormality.

In 1944 the patient had an injury to his back and head, which was followed by difficulty in walking and micturition, but he apparently recovered completely. He had no other serious illnesses.

The patient worked for 31 years with the G.P.O. in a postal sorting department, except during the war, when he was associated with an artillery unit. His only hobby has been horticulture which has brought him into contact with fertilizers, but he has never worked with heavy metals or other chemicals. For the past few years he has been a caretaker.

Family history There is no overt history of neurological disease in his parents, sibs, children, or grandchildren. No nerve conduction studies, however, have been performed on the relatives.

Investigations No neoplastic disease was revealed. A pyruvate tolerance test was normal; a myelogram suggested thickening of the nerve roots; the cerebrospinal fluid was slightly xanthochromic, contained 2 lymphocytes per c.mm. and protein $1,600 \mathrm{mg} . \%$ with a marked excess of globulin. Sural nerve biopsy (R.O.W.) showed hypertrophic neuropathy. An E.M.G. (Dr. P. K. Thomas) confirmed the existence of a mixed motor and sensory neuropathy. The magnitude of the slowing was consistent with a hypertrophic neuropathy.

Treatment A course of steroid therapy was commenced.

CASE 3 G.H. (no. A.221185), a 21-year-old man, appeared normal at birth but at the age of 2 years he had difficulty in standing due to a marked external rotation of the hips. He developed a kyphoscoliosis at the age of 5-6 years which progressed. Aged 12, he had a triple arthrodesis of the left ankle and a rotation osteotomy of the right tibia. He walked well, until the age of 15 years when his legs became progressively weaker and he experienced abnormal sensations in them. He was soon unable to walk, but later, with physiotherapy, he was able to walk again with the aid of crutches.

On examination, during his admission to Guy's 8 Hospital in March 1964 under Dr. M. J. McArdle, he was found to have a gross kyphoscoliosis and weakness in all his limbs which was more marked distally. The cranial nerves were normal except for moderate bilateral seventh nerve palsies. Tone was normal in the arms but there was hypotonia of the legs with absent reflexes; plantar responses were not elicited. He showed ataxia of the legs and gross impairment of vibration and joint position sense in both legs and hands, and to a lesser extent in the arms. Light touch and pain sensations were, however, less affected but still showed impairment distally in all four limbs. The greater auricular and sural nerves were grossly thickened, and were easily visible and palpable through the skin.

He had had numerous chest infections.

The patient worked as a tailor but this was too heavy for him so he changed to clerical work.

Family history A sister aged 14 years is also a patient of Dr. M. J. McArdle and has hypertrophic neuropathy, but there is a brother who appeared to be normal. No abnormality has been detected in other relatives, but nerve conduction studies have not been performed.

Investigations The blood picture was normal. The cerebrospinal fluid pressure was $145 \mathrm{~mm}$. $\mathrm{Hg}$; no cells were observed but the protein content was $850 \mathrm{mg}$. per $100 \mathrm{ml}$. with a marked excess of globulin. A pyruvate tolerance test was normal. Hypertrophic neuropathy was diagnosed from a muscle biopsy (Dr. J. B. Cavanagh) and confirmed by sural nerve biopsy. 
METHODS

Sural nerve biopsies were taken from all patients at or near the level of the lateral malleolus. The normal control sural nerve biopsies were obtained under general anaesthesia from a 6-month-old baby boy with suspected Tay Sach's disease and from a 35-year-old man at the commencement of an operation for stripping the short saphenous vein. No abnormality could be found in either nerve but this does not mean that they were completely normal as our experience in normal sural nerve ultrastructure is obviously limited.

The pathological sural nerves were taken from each of the three patients under local anaesthesia.

All the specimens were cut into short lengths and immersed either in $3 \%$ glutaraldehyde in $0.67 \mathrm{M}$ cacodylate buffer at $p \mathrm{H} 7.4$ for three hours at $4^{\circ} \mathrm{C}$., or fixed directly in $1 \%$ osmium tetroxide in veronal acetate buffer for four hours (Palade, 1952). The glutaraldehyde-fixed material was subsequently washed for 18 hours in a cacodylate-buffered sucrose solution and then postosmicated for two hours. Following dehydration in graded ethanol and propylene oxide the nerves were embedded in araldite. Thin sections were cut on a Huxley Cambridge microtome and viewed in an RCA EMU $3 e$ electron microscope. The specimens were stained by varying combinations of $1 \%$ phosphotungstic acid in absolute ethanol, $1 \%$ aqueous potassium permanganate, a saturated solution of uranyl acetate in $50 \%$ ethanol and $0.4 \%$ lead acetate in water.

Thick araldite sections, $2-3 \mu$, were also cut on the Huxley microtome and stained in $1 \%$ toluidine blue for light microscopic examination.

Pieces of nerve from the biopsies were prepared for light microscopy by fixation in formalin or glutaraldehyde, and either embedded in paraffin wax or soaked in $30 \%$ glycerine for teasing. Transverse and longitudinal sections of paraffin-embedded material were stained by haematoxylin and eosin, Van Gieson, Loyez, and Glees and Marsland techniques. The teased preparations were stained either in $1 \%$ osmium tetroxide for 24 hours, or oil-red-O solution and haematoxylin.

Measurements on electron micrographs were made with a Pye travelling microscope.

\section{RESULTS}

NORMAL NERVE The normal human sural nerve contained myelinated and non-myelinated nerve fibres in several fasciculi each surrounded by a perineurium. Collagen and capillaries were present within the fasciculi, orientated parallel to the nerve fibres.

The cytological details of the different components in the nerve were demonstrated with the electronmicroscope. The larger axons were surrounded by a myelin sheath formed by the Schwann cell, whereas the smaller diameter axons were unmyelinated and simply invaginated into Remak cells (Figs. 4-6). Causey (1960) considered the Schwann
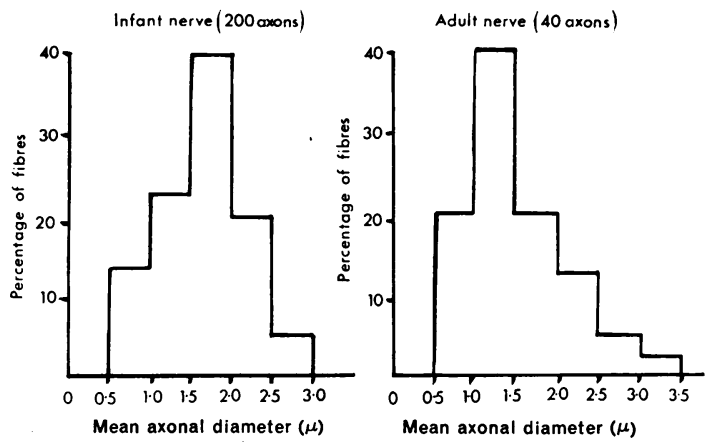

FIG. 1. Histograms showing the size distribution of nonmyelinated axons in normal infant and adult sural nerves. The peak falls between 1 and $2 \mu$ in both nerves and very few non-myelinated axons are more than $3 \mu$ in mean diameter.

cells associated with myelinated and unmyelinated axons to be very similar, but, in this study it has been useful to make a distinction between these cells. Therefore, those cells associated with the larger myelinated axons have been termed Schwann cells, whereas those cells invaginating unmyelinated axons have been called Remak cells.

One of the main features of the pathological material studied in this communication was the loss of normal myelin sheaths, so it was necessary to establish criteria for distinguishing between truly non-myelinated fibres, and axons which had lost their myelin sheaths. The range of axon diameters found in the normal infant and adult nerve is shown in Figure 1. There was a peak between 1 and $2 \mu$, for the unmyelinated fibres, and no myelinated axons were observed below 3.5 to $4 \mu$ diameter.

There was a considerable difference between the ages of the youngest (6 yr.) and the oldest (61 yr.) in the group of three patients with hypertrophic neuropathy, so that it was important to study briefly some of the normal variations in peripheral nerve structure between infants and adults. In addition to the increase in axonal diameters and appearance of the myelin sheaths, there were some well-defined differences between the Remak cells associated with non-myelinated axons in the infant and the adult. The non-myelinated axons in the infant were usually in groups with very little Remak cytoplasm associated with them (Fig. 4). A similar arrangement has been described in human foetal nerves by Cravioto (1965), Gamble and Breathnach (1965), and Gamble (1966). The axons in the adult nerve were, by contrast, often quite widely separated and associated with a greater volume of Remak cytoplasm that was usually in the form of thin processes closely stacked in layers (Fig. 5). 


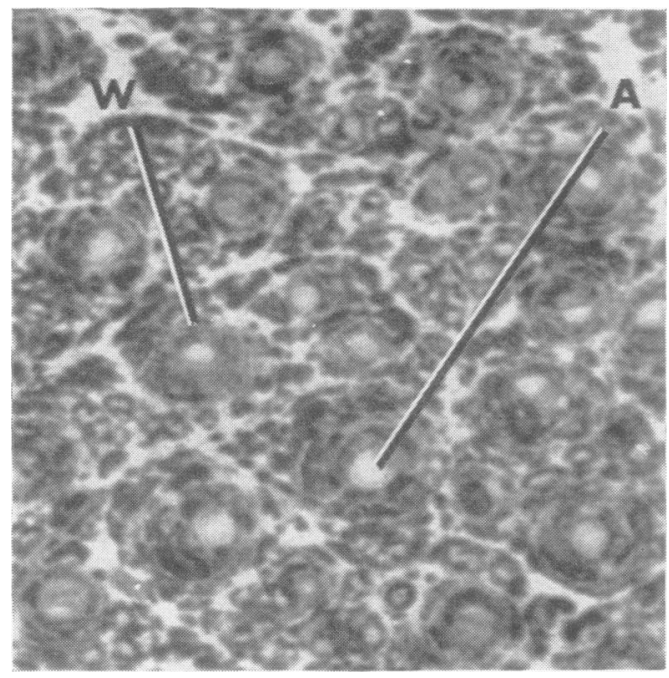

FIG. 2. T.S. Sural nerve from case 1. There is a regular array of 'onion-bulb' whorls $(W)$ with a pale central axon (A). No normal myelin sheaths are present. Light micrograph of araldite section stained with $1 \%$ toluidine blue. $\times 530$.

FIG. 3. T.S. Sural nerve (case 3). There is an increase in the number of nuclei in the nerve, many of which are found in the 'onion-bulb' whorls $(W)$. A few myelin sheaths $(M)$ are visible, though they are reduced in thickness. Light micrograph, paraffin section, Loyez stain. $\times 530$.

FIG. 2.

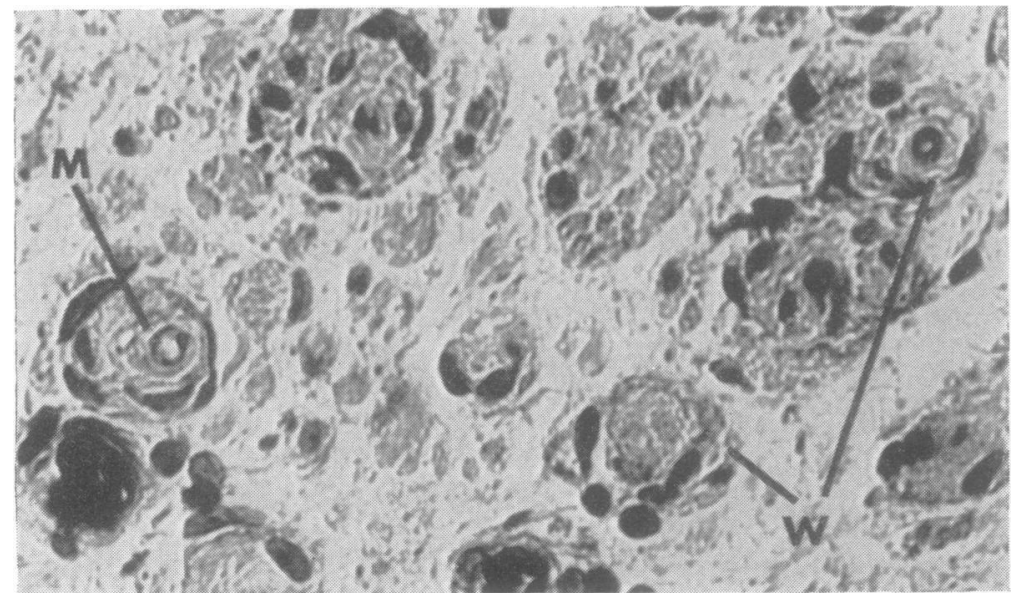

FIG. 3.

Not infrequently, moreover, these processes were extended and appeared partially to encircle a myelinated nerve fibre (Fig. 5).

The identification of Schwann and Remak cell processes, in the pathological nerves when axons had degenerated, was made mainly on the appearances of their cytoplasm and the presence of a basement membrane. The only other cells commonly found free in the endoneurium were fibroblasts and an occasional macrophage and mast cell; none of these cells usually possessed a basement membrane. Capillary and perineurial cells were normally associated with each other and, though they possessed basement membranes, there were marked cytoplasmic differences between them and the Schwann or Remak cells.
The cytological details of the axons varied with the methods of fixation. In the glutaraldehyde-fixed material the axons contained $200 \AA$ neurotubules and neurofilaments $100 \AA$ in diameter; both were orientated approximately longitudinally but periodically approached the plasma membrane. These structures did not appear to be well-preserved in tissue fixed in osmium tetroxide alone, although two types of filament were found in this material, $150 \AA$ and $100 \AA$ in diameter. The axonal mitochondria were disposed longitudinally and appeared roughly circular in cross-section. There were a few vesicles in the axonal cytoplasm but no recognizable granular endoplasmic reticulum.

The structure of the normal human myelinated nerve fibres, the myelin sheaths, and nodes of 


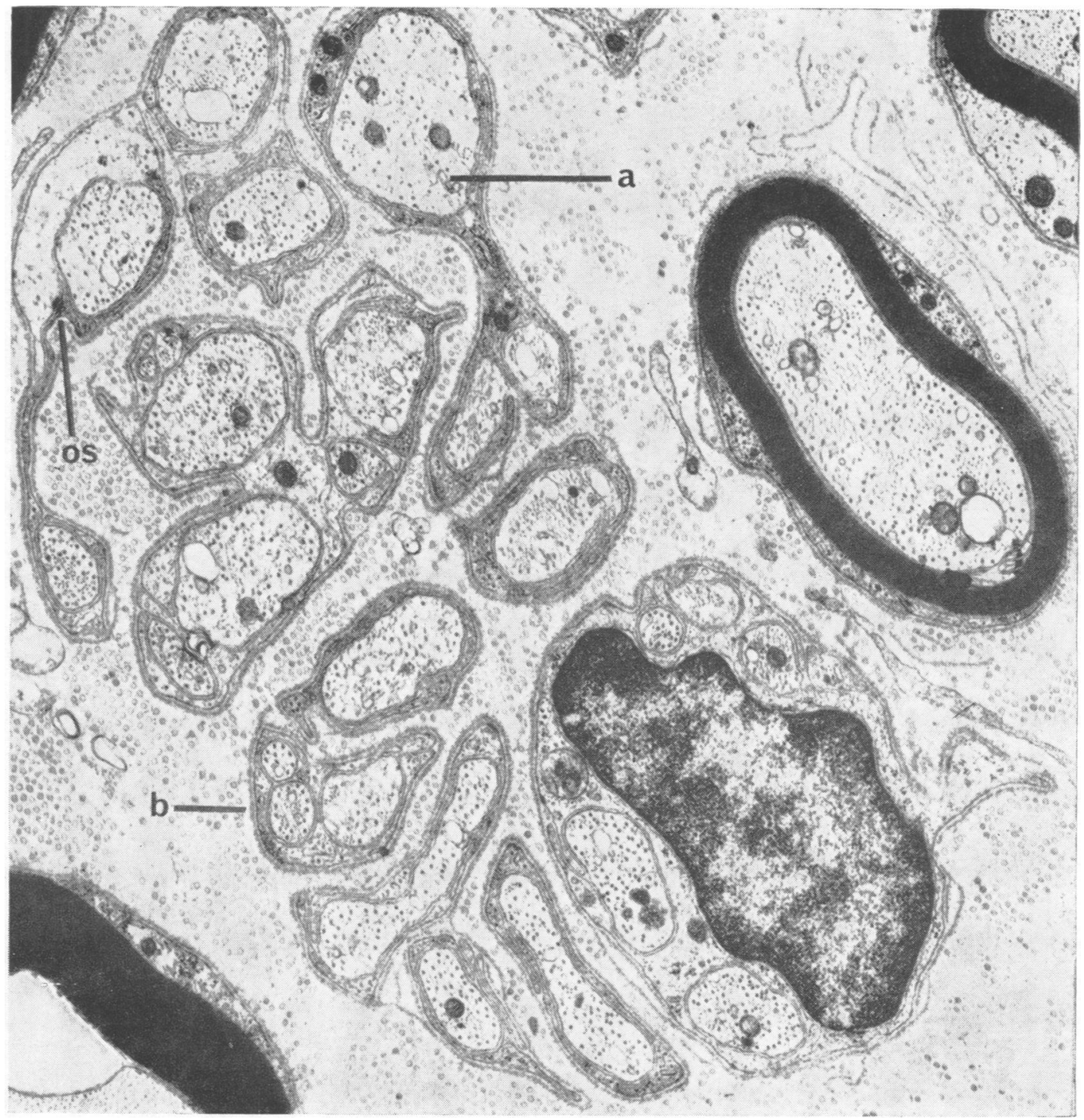

FIG. 4. T.S. Normal infant nerve. Non-myelinated axons (a) are surrounded by very little Remak cytoplasm. The mesaxons are usually short, and osmiophilic zones are present on them (os.). Basement membrane (b). Lead stained. $\times 12,000$. 

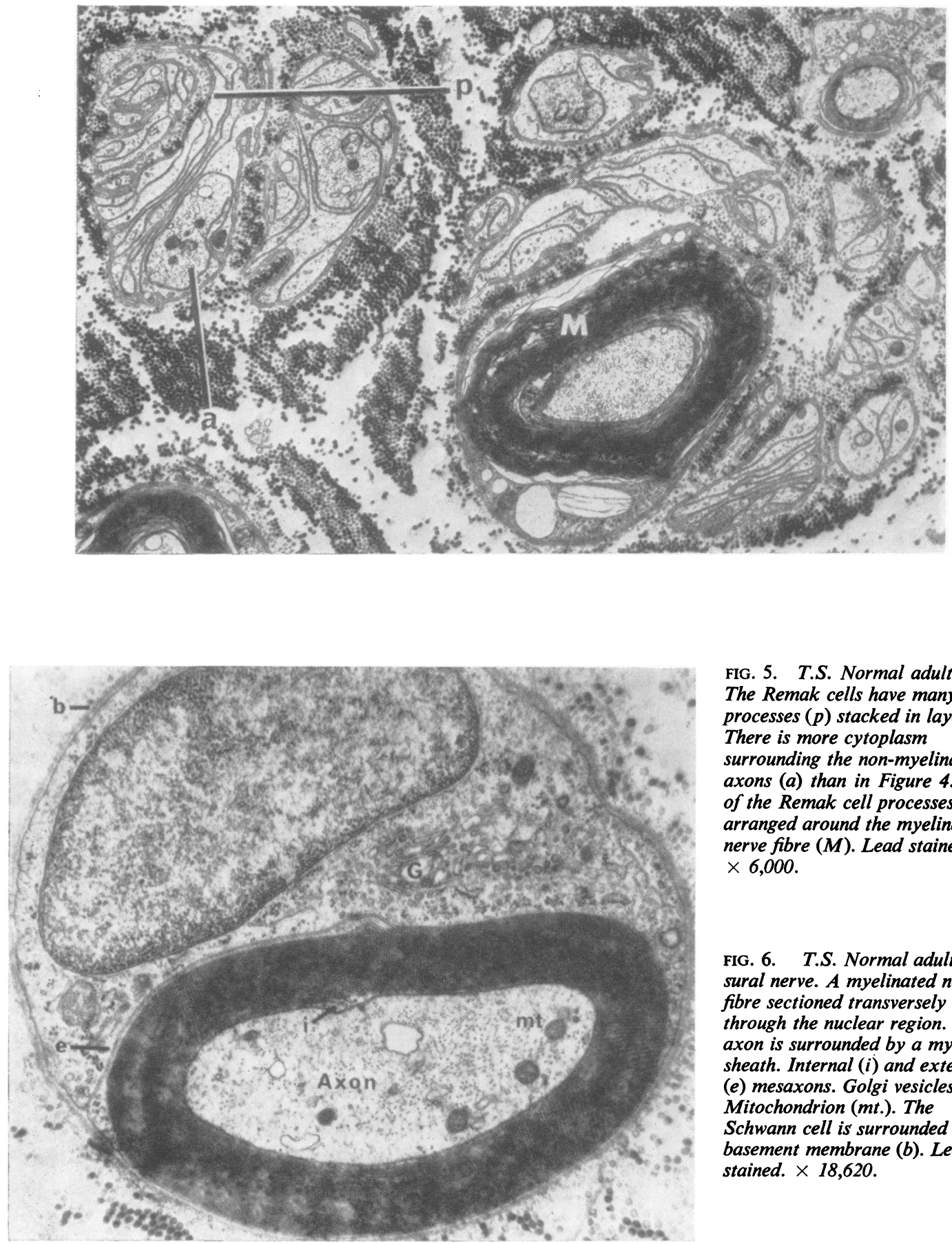

FIG. 5. T.S. Normal adult nerveo 응

The Remak cells have many processes $(p)$ stacked in layers. There is more cytoplasm surrounding the non-myelinated axons (a) than in Figure 4. Some of the Remak cell processes are arranged around the myelinated nerve fibre $(M)$. Lead stained. $\times 6,000$.

FIG. 6. T.S. Normal adult sural nerve. A myelinated nerve fibre sectioned transversely through the nuclear region. The axon is surrounded by a myelin sheath. Internal (i) and external (e) mesaxons. Golgi vesicles $(G)$ Mitochondrion (mt.). The Schwann cell is surrounded by a basement membrane (b). Lead stained. $\times 18,620$. 
Ranvier was very similar to that described in various mammalian (Webster and Spiro, 1960; Ross, 1964) and avian species (Weller, 1965). The main features seen in a cross-section of a human myelinated fibre are illustrated in Figures 6 and 7. The myelin had a periodicity of approximately $120 \AA$ in both glutaraldehyde- and osmium-fixed material.

Osmiophilic areas resembling those described by Gamble (1966) along the mesaxons of nonmyelinated nerves were also observed here along the external mesaxons of myelinated fibres (Figs. 6 and 7). The layers of cell membrane were partially fused to form an interperiod line. These structures were similar to the zonula occludens described in various epithelial tissues by Farquhar and Palade (1963).

The individual nerve fibres were separated by endoneurial collagen which was, in general, orientated longitudinally. Small bundles of collagen fibres were occasionally observed invaginated into sheath cells, especially the Remak cells in the older person (Gamble and Eames, 1964). It was rare, however, to find the collagen in direct contact with the Schwann cell membrane in the normal nerve, for there was almost invariably an intervening basement membrane.

PATHOLOGICAL MATERIAL EXAMINED BY LIGHT MICROSCOPY The diagnosis of hypertrophic neuropathy was made with the light microscope in all three cases.
The nerve from the 6-year-old child (case 1) illustrated the histological features of the syndrome with the large diameter axons situated in the centre of whorls composed of layers of cells and collagen (Fig. 2). There were no normal myelin sheaths present in the biopsy from case 1 and the very thin abnormal myelin surrounding some of the fibres was only just within the resolving power of the light microscope. The same basic proliferative cellular pattern was evident in the nerves of case 2 (Fig. 3) and case 3. The whorls in these biopsies were, however, more irregular in size, and the myelin sheaths around the central axons were often detectable, though still greatly reduced in thickness. There was also more oedema in the endoneurial spaces of the nerves from the two older patients.

The teased preparations demonstrated the segmental distribution of the myelin loss with gross variation of myelin thickness and internodal length along each fibre. Thinly myelinated segments were observed adjacent to segments where the myelin had been lost. These preparations also showed the cellular sheath encasing the fibres; it was this sheath-like arrangement which appeared as a whorl in the transverse section.

PATHOLOGICAL MATERIAL EXAMINED BY ELECTRON MICROSCOPY The 'onion-bulb' whorls were well demonstrated in the low-power electron micrograph from the 6-year-old child (Fig. 8). In this specimen,

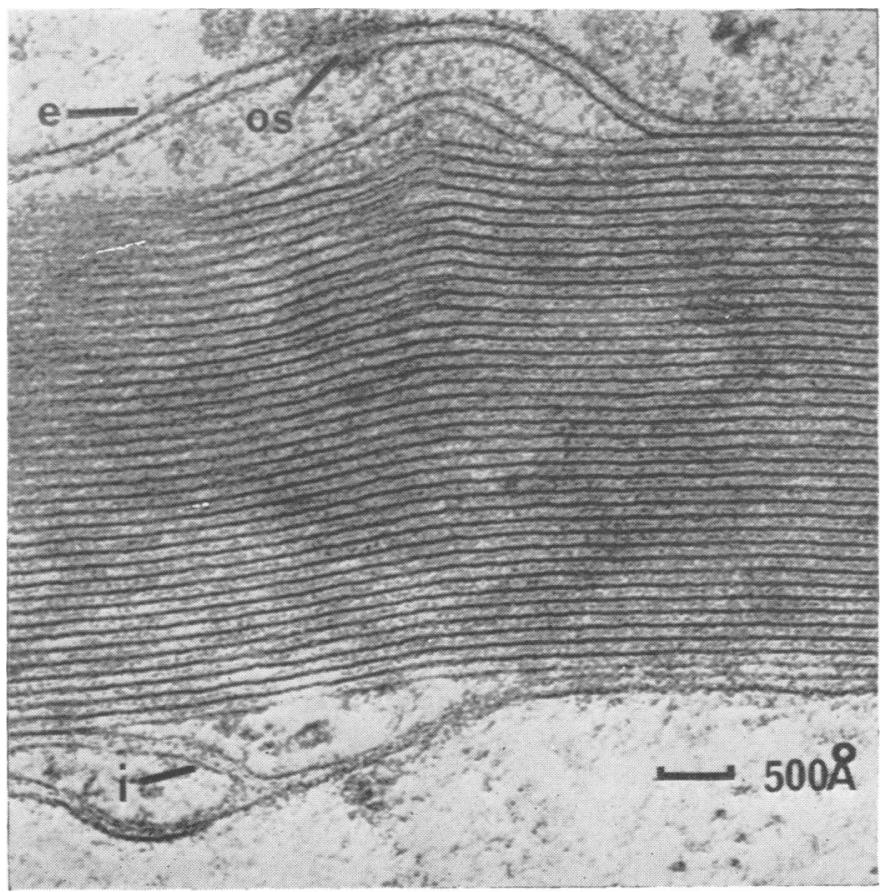

FIG. 7. Normal myelin showing the dense period lines $120 \AA$ apart, with indistinct interperiod lines. There is an osmiophilic area (os) along the external mesaxon $(e)$ where two of the layers are fused to form an interperiod line. Internal mesaxon (i). Lead stained. $\times 150,000$. 
the whorls were discrete and separated from each other by large amounts of collagen. The pattern was very much more irregular in the nerves from the older patients, but the basic cellular arrangement was similar. At the centre of each whorl there was usually a single axon, surrounded by its Schwann cell, although there were sometimes two axons, or none at all, in this position. The axons were large and in the normal adult nerve would have been surrounded by thick myelin sheaths, but in the pathological nerves the myelin sheaths were either very thin or absent and there was very little normal myelin present (Figs. 8 and 9).

The majority of the elongated cell processes which formed the concentric lamellae of the whorls seemed to be derived from Schwann and Remak cells (Fig. 9). They were surrounded by basement membranes and many contained non-myelinated axons (Fig. 10). Some fibroblasts were included in the whorl formations but their presence often seemed to be coincidental for they were not usually orientated in the same concentric manner as the Schwann cells (Fig. 9). It was not always clear from which Schwann cells the processes arose, for, as the teased preparations clearly showed, the Schwann and Remak cells were so short and were lying so close together, that it would only be possible to trace their processes by extensive serial sectioning. The processes nearest the centre of the whorl may have been extensions of the central Schwann cell, and the empty basement membrane profiles may have represented the sites of cellular processes which had since moved away. Some of the more peripheral cell processes, however, apparently arose from Remak cells containing axons which, from their size, were probably originally non-myelinated (Fig. 10). This was particularly common in the two older patients (cases 2 and 3 ) where the small nonmyelinated axons were often found in the cells taking part in the whorls. It was difficult to be certain, however, which axons were originally unmyelinated and which axons were perhaps regenerative sprouts from the larger myelinated axons. All the axons seemed to have the same structure, so that if the myelin sheaths were destroyed the only remaining difference would be that of size. If this in turn were no longer reliable, it would be very difficult to distinguish between regenerating axons and those which were originally non-myelinated. However, no definite indication of collateral sprouting such as a large axon and a very thin axon in the same Schwan cell was observed. Therefore, most of the axons less than $3 \mu$ in diameter without myelin sheaths were tentatively classified as being originally non-myelinated.

One phenomenon which was particularly common in the young adult patient (case 3) was the invagination of collagen bundles by Remak cells containing non-myelinated axons less than $3 \mu$ in diameter. This was much more common than in normal adult nerves and the collagen bundles were often subtended by long 'mesaxons' (Fig. 10). There was, however, almost always a basement membrane separating the bundles of collagen from the Remak cell membrane although a small number of collagen fibres did occur within the bounds of basement membranes in similar situations to those described during the repair stages of Wallerian degeneration (Nathaniel and Pease, 1963b; Thomas, 1966). Collagen invagination by Schwann cells was less commonly found.

It was difficult to estimate what proportion of the axons had degenerated in the diseased nerves. There may have been some Wallerian degeneration, for there seemed to be a reduction in the numbers of both large axons and true non-myelinated axons. The loss of axons may have been a stimulating factor for the invagination of collagen by the Remak and Schwann cells (Gamble and Eames, 1964). Despite the extensive loss of myelin, however, the remaining axons, often 6-7 $\mu$ in diameter, appeared to be structurally normal with $200 \AA$ neurotubules, $100 \AA$ neurofilaments and mitochondria within the axoplasm.

The myelin sheaths in the normal adult nerve were usually compact in the internodal regions, and in general the larger diameter axons were surrounded by the thicker myelin sheaths. There was a great variation in myelin thickness in all three pathological nerves. In case 1 there were many large axons $5-6 \mu$ in diameter with no myelin sheaths or only five or 10 myelin lamellae surrounding them (Figs. 8 and 9); no sheaths of normal thickness were observed in this nerve. A similar situation existed in cases 2 and 3, but in each of these two biopsies a few myelin sheaths of normal thickness were present. There were, however, in one otherwise apparently normal myelin sheath in case 3 large areas where the myelin was not compact. These regions were similar to Schmitt-Lantermann incisures but they were much more irregular and involved much larger areas of the myelin sheath than the normal incisures.

Abnormally short internodal segments of myelin between the nodes of Ranvier were observed in the teased preparations of the peripheral nerves in hypertrophic neuropathy (Thomas and Lascelles, 1967). In the normal adult nerve the internodal length is approximately proportional to the thickness of the myelin sheath (Vizoso and Young, 1948) and many exceeded $1 \mathrm{~mm}$. in length. The nucleus of the Schwann cell is usually situated midway between the nodes of Ranvier in the internodal portion of the fibre. The extremely thinly myelinated, 

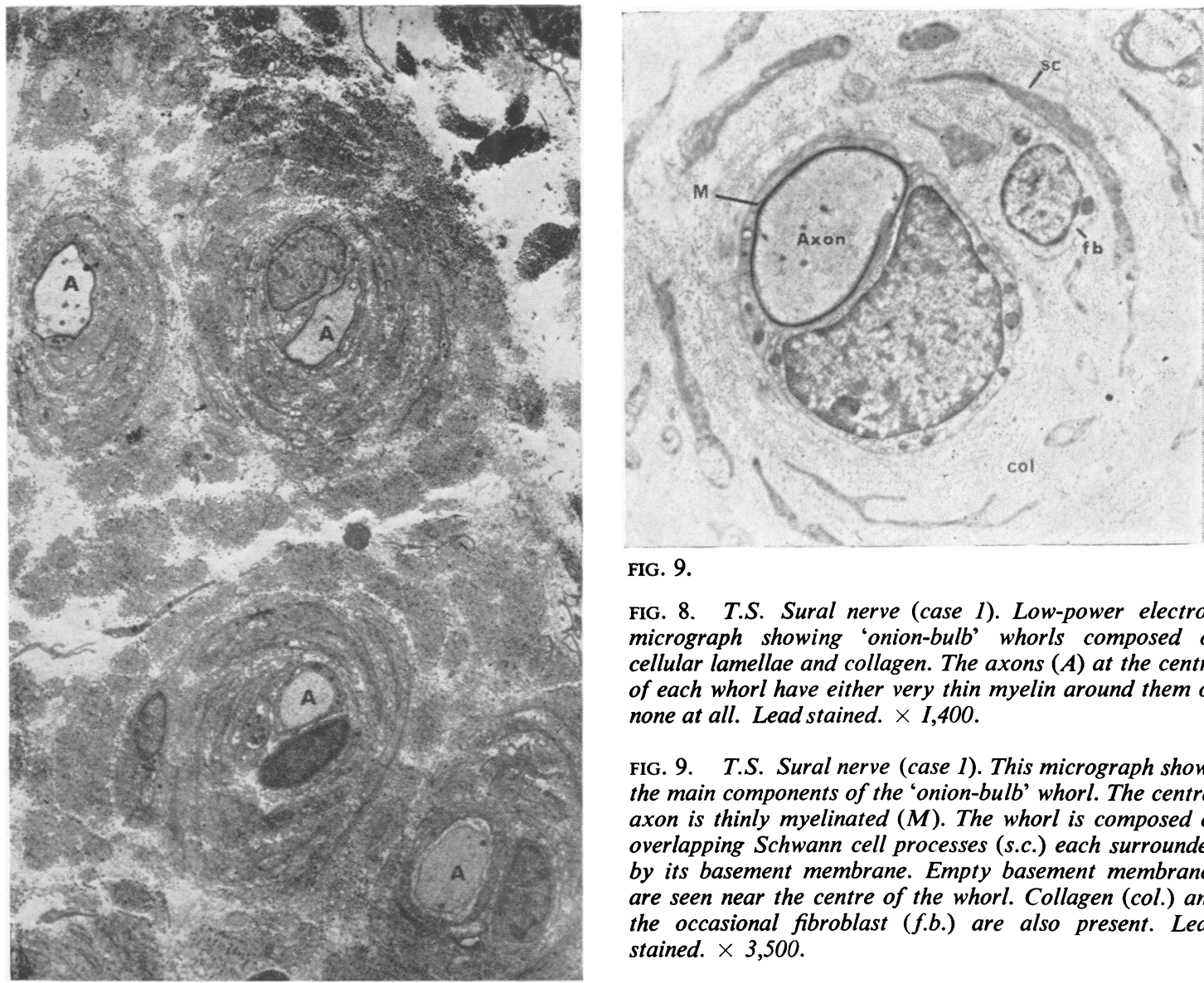

FIG. 9.

FIG. 8. T.S. Sural nerve (case 1). Low-power electron micrograph showing 'onion-bulb' whorls composed of cellular lamellae and collagen. The axons $(A)$ at the centre of each whorl have either very thin myelin around them or none at all. Lead stained. $\times I, 400$.

FIG. 9. T.S. Sural nerve (case 1). This micrograph shows the main components of the 'onion-bulb' whorl. The central axon is thinly myelinated $(M)$. The whorl is composed of overlapping Schwann cell processes (s.c.) each surrounded by its basement membrane. Empty basement membranes are seen near the centre of the whorl. Collagen (col.) and the occasional fibroblast (f.b.) are also present. Lead stained. $\times 3,500$.

FIG. 8 .

FIG. 10.

T.S. Sural

nerve (case

2). A Remak

cell with $a$

non-mye-

linated axon

(a) invagina-

ted into it,

has cyto-

plasmic

processes

extending

around $a$

myelinated

fibre. Other

Remak cells

are seen in-

vaginating

bundles of

collagen

(col.), often

with quite

long

mesaxons.

Potassium

permanganate

stained.

$\times 10,860$.

FIG. 10 . 


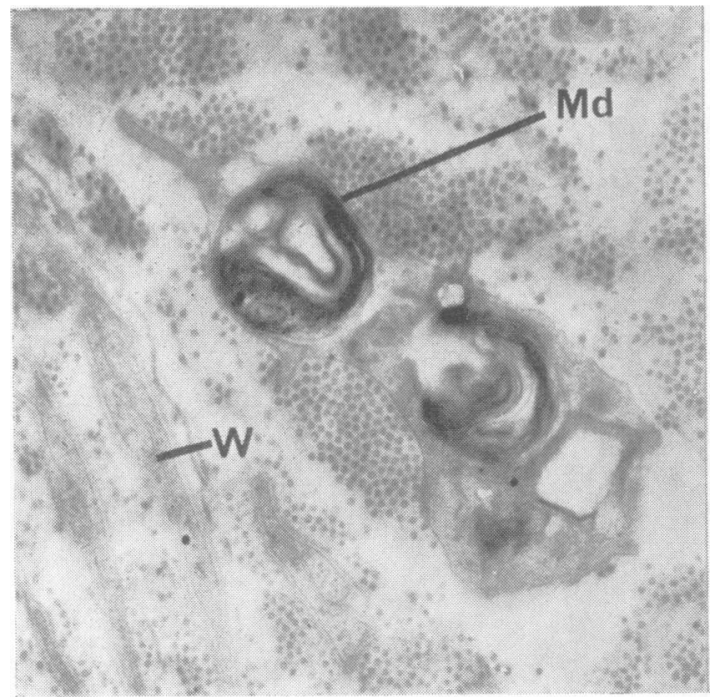

FIG. 11. T.S. Sural nerve (case 1). Demyelination. Endoneurial macrophage containing myelin debris $(M d)$. The outer layers of an 'onion-bulb' whorl are visible $(W)$. Lead stained. $\times 10,600$.

FIG. 14. T.S. Sural nerve (case 1). A $4 \mu$ axon with no myelin sheath surrounding it, and very little Schwann cytoplasm (s.c.) either. The basement membrane (b) is continuous, and except at one small point $(c)$; it is even interposed between the Schwann cell processes and the axon. Lead stained. $\times 15,900$.

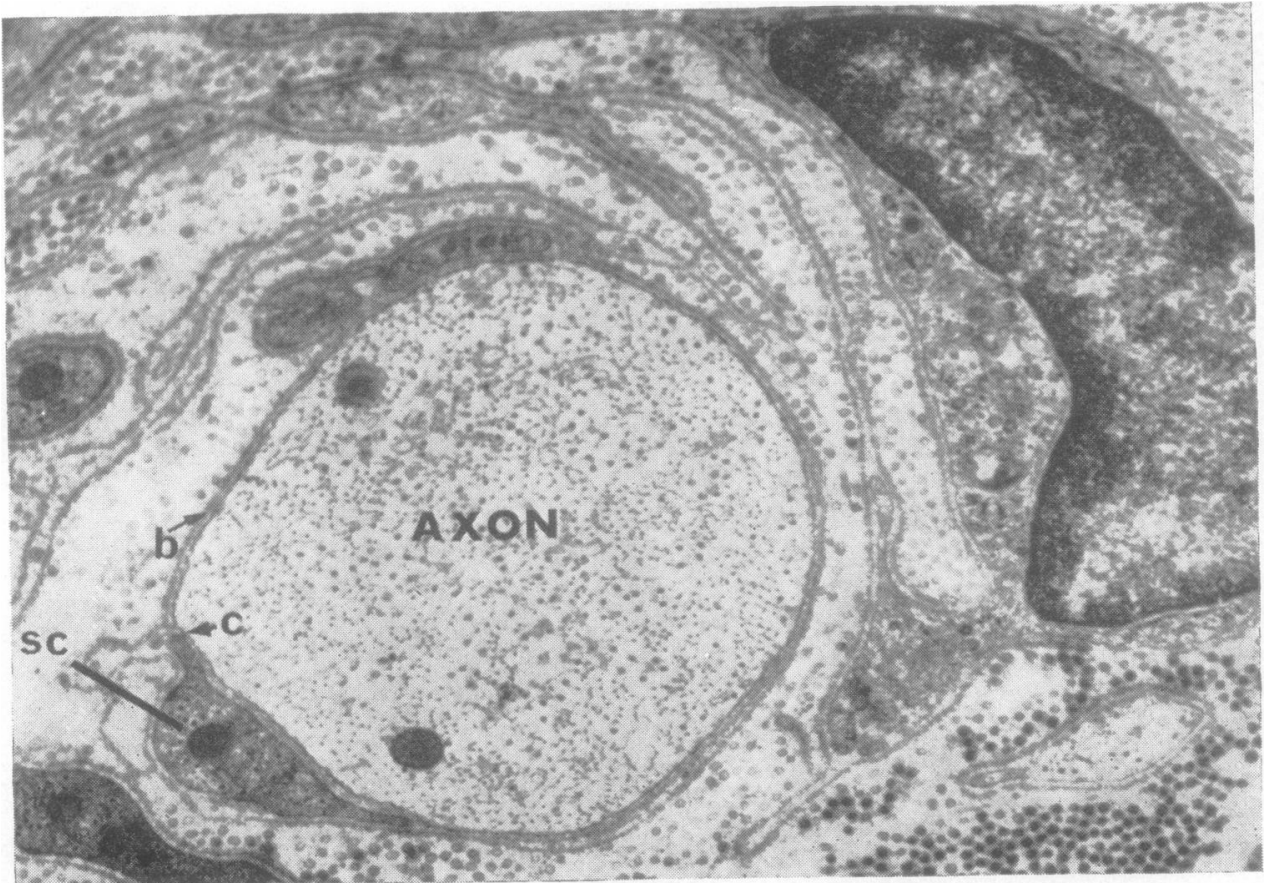




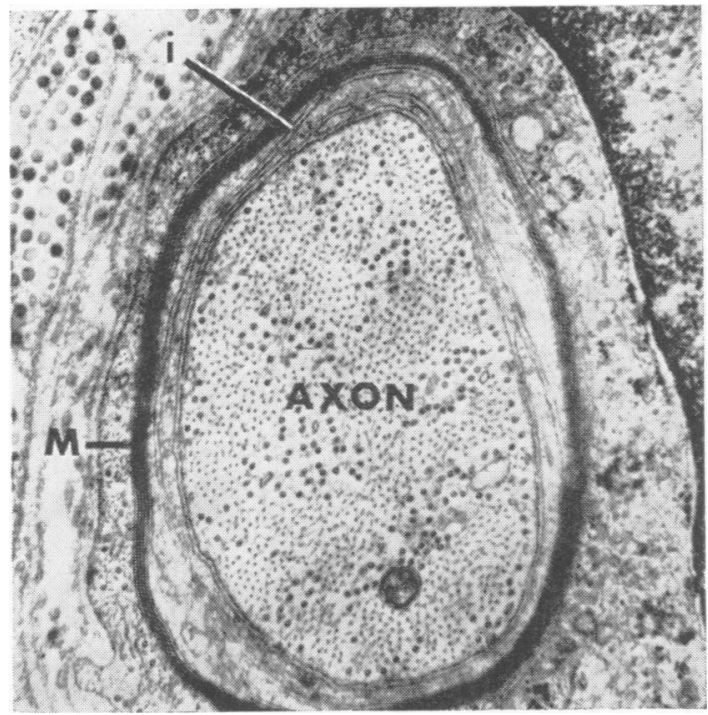

FIG. 12. T.S. Sural nerve (case 1). Remyelination. A thin outer layer of compact myelin $(M)$ is separated from the axon by a layer of Schwann cell cytoplasm with a long internal mesaxon (i) running through it. Lead stained. $\times$ 27,000 .

FIG. 15. T.S. Sural nerve (case 3). A bizarre situation where the central axon-myelin-Schwann cell complex has been invaginated and myelinated by another Schwann cell. Two layers of basement membrane (b) and a layer of collagen (col.) separate the inner and outer Schwann cells. Centriole (cen.). Lead stained. $\times 24,000$.

FIG. 12 .

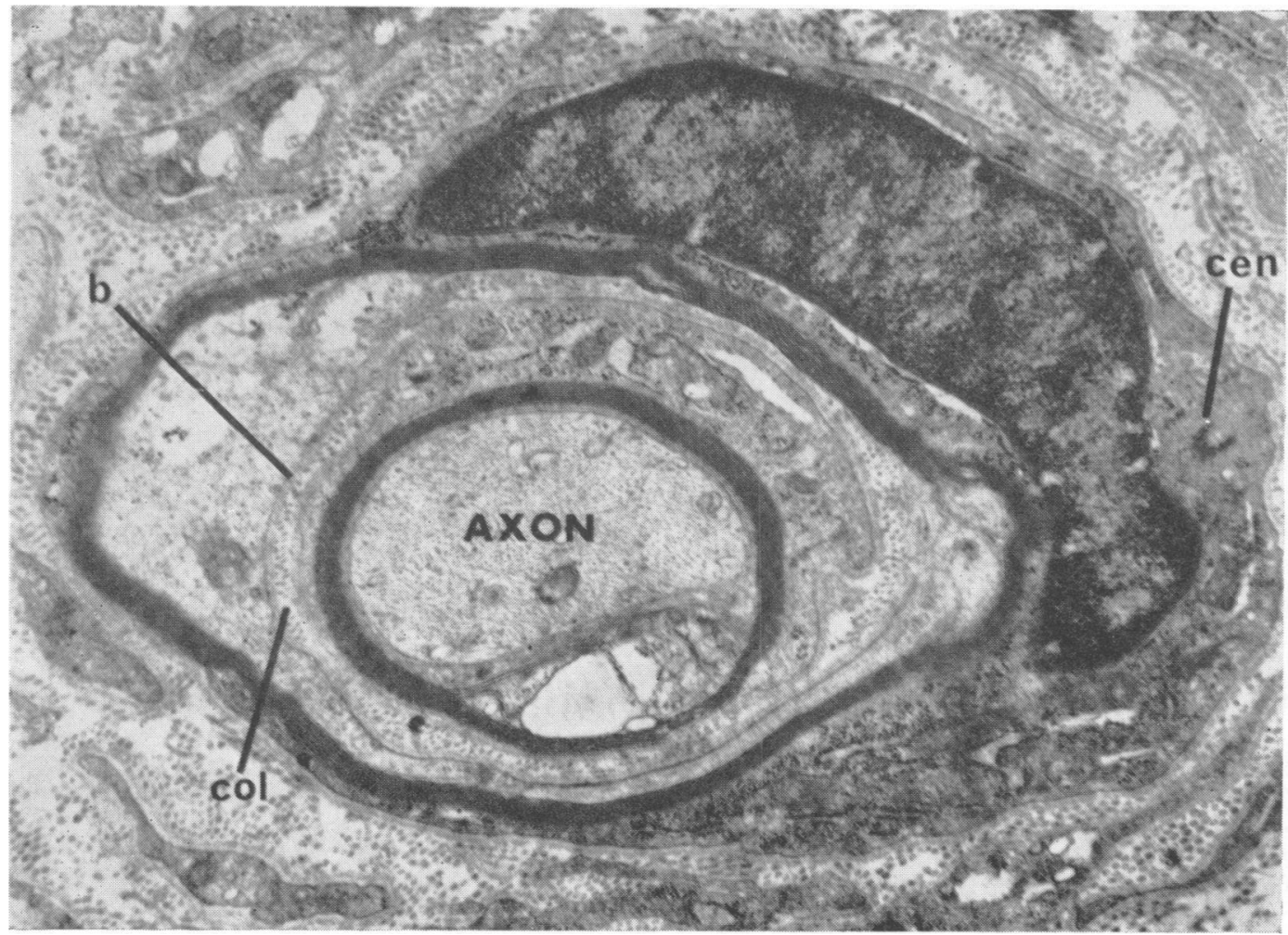

FIG. 15. 


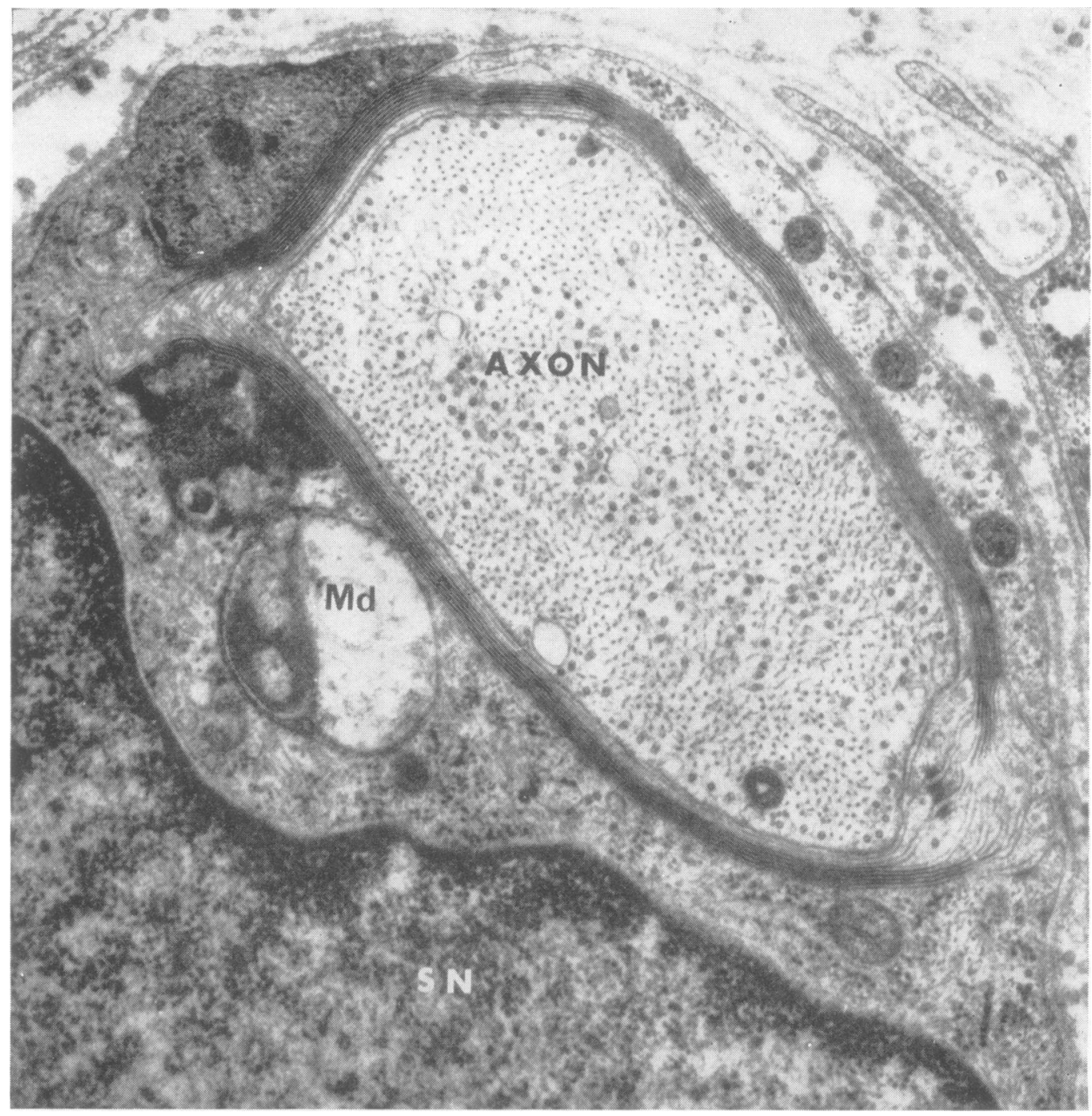

FIG. 13. T.S. Sural nerve (case 1). Remyelination. Some areas of the thin myelin sheath are not compacted. Myelin debris (Md.) is present in the Schwann cytoplasm possibly from previous demyelination. The axon appears normal and contains many neurotubules and filaments. Schwann cell nucleus $(S N)$. Lead stained. $\times 31,800$.

short, internodes in the pathological nerves were confirmed in longitudinal sections examined electronmicroscopically, where the nodes were often only the length of a nucleus apart; segments were also observed where there was no myelin sheath at all. Nodes of Ranvier, recognizable by the paranodal myelin end loops, were frequently seen cut in crosssection, and were often situated in a perinuclear region; this was again an indication of the very short internodal lengths.

Many of the Schwann cells seemed to be hyper- trophied in the pathological nerves, with large amounts of cytoplasm, endoplasmic reticulum, and numerous mitochondria. The normal Schwann cell had a rather tenuous layer of cytoplasm outside the myelin sheath in the internodal portion, but with more cytoplasm and organelles, in the perinuclear and paranodal regions (Williams and Landon, 1963). As the Schwann cells in the pathological nerves, however, were very much shorter than in the normal nerves the volume of cytoplasm per cell might not, in fact, have been increased. 
Evidence of both demyelination and remyelination was found in the nerves of all three pathological biopsies in this study. Myelin debris, still retaining its lamellar pattern, was present in Schwann cytoplasm in close proximity to demyelinated axons and presented a similar appearance to the early stages of experimental demyelination (Webster et al., 1961; Weller, 1965). Lamellated myelin debris was also found in endoneurial macrophages (Fig. 11). Later stages of myelin breakdown were represented by non-lamellated neutral lipid droplets present in Schwann cells enclosing demyelinated axons 5-6 $\mu$ in diameter.

As mentioned above, many large axons had no myelin sheaths, though most were surrounded by a layer of Schwann cytoplasm. Sometimes, even this coating was deficient leaving the axon with no cellular investment over some three-quarters of the circumference (Fig. 14). The axon in Fig. 14 was in contact with a basement membrane over its whole circumference including the regions opposite the Schwann cell processes, except perhaps in one small area. It was not possible without serial sections to determine the length of axon which was denuded of satellite cell covering, but in a normal nerve, this $4 \mu$ diameter axon would probably have very little of its surface devoid of investing Schwann cells even at a node of Ranvier. Despite the virtual absence of cellular investment the axon appeared to be structurally normal.

Many of the large axons in this disease had only a very thin myelin sheath surrounding them, and some presented features seen in normal myelination in peripheral nerves (Geren, 1954; Cravioto, 1965). The inner layers of the myelin sheath were often not compacted while several outer layers formed compact myelin (Fig. 12); some axons had as many as four turns of mesaxon around them with no compaction of myelin. The presence of myelin debris in the Schwann cytoplasm during myelination (Fig. 13) suggested that this was a process of remyelination following segmental demyelination similar to that described by Webster et al. (1961) in experimental diphtheritic neuropathy.

A process which could only be considered as aberrant remyelination is shown in Fig. 15 where the outer Schwann cell appeared to be remyelinating a complete axon-myelin-Schwann-cell complex together with a layer of endoneurial collagen. Another variation from normal Schwall cell structure which might indicate some abnormality of function was the occurrence of nuclei with corkscrew shaped tails. These aberrant nuclei occurred not only in cells associated with large demyelinated fibres, but also in cells which were surrounding small non-myelinated axons.

\section{DISCUSSION}

The three patients with hypertrophic peripheral neuropathy presented in this report showed certain differences in their clinical histories. The age of onset, the speed with which the symptoms progressed, and the family history, which was doubtful in case 1 , seemed to be absent in case 2 but was positive in case 3 , were all points on which the patients varied clinically. However, the main character of the disease was similar, for, in all three cases there were signs of a progressive motor and sensory neuropathy affecting the lower limbs more severely than the upper limbs. The more discriminative aspects of sensation tended to be affected and there was an associated profound slowing of conduction in the nerves.

The histological changes in the peripheral nerves were also strikingly similar in all three biopsies, especially at the ultrastructural level. The cellular whorls observed with the light microscope have been shown with the electron microscope to be composed of overlapping Schwann or Remak cell processes arranged in concentric layers around a central axon. The layers were separated by endoneurial collagen which was markedly increased in amount throughout the affected nerve. It is difficult with the light microscope to distinguish Schwann and Remak cells from connective tissue cells in this abnormal pattern (Cammermeyer, 1956), and Dejerine and Sottas (1893) originally maintained that the cellular proliferation was entirely in the connective tissue and that the Schwann cell and axon played only a passive role. They suggested that the loss of myelin and axons was due to compression by the hyperplastic connective tissue elements. Later authors (Roussy and Cornil, 1919) ascribed the hyperplasia to Schwann cells, but Cammermeyer (1956) was still in doubt concerning the exact identity of the cells.

Another major feature of this disease is the loss of myelin in the peripheral nerves. The segmental character of the demyelination was well described by Dejerine and André-Thomas (1906) who noted that the myelin sheaths varied in thickness along the length of the fibres, and at times, they would completely disappear. These findings have been confirmed by the present electron microscopic study.

The disruption of myelin sheaths is probably continuously progressive, for myelin breakdown products were identified fairly frequently with the electron microscope in Schwann cells and endoneurial macrophages.

Cammermeyer (1956) suggested that the loss of myelin was by a process of 'delamination' whereby the myelin sheaths became thinner and thinner and finally disappeared. It is more probable, however, that the myelin breakdown follows a similar course 
to that described in experimental diphtheritic neuropathy, where, in the smaller fibres at least, the myelin sheath is split longitudinally by the action of lysosomal enzymes produced by the Schwann cell (Weller, 1965). The myelin debris then becomes separated from the axon (Webster et al., 1961) and is broken down by the Schwann cell and by endoneurial macrophages (Weller, 1965; Weller and Mellick, 1966).

The very thin myelin sheaths around large axons, described by many authors and also here, probably represent stages in the remyelination of these axons following myelin breakdown. The electron micrographs of these fibres showed many of the features of both normal myelination (Geren, 1954; Cravioto, 1965; Gamble, 1966) and remyelination (Webster et al., 1961; Nathaniel and Pease, 1963a). There were often several turns of uncompacted myelin and Schwann cytoplasm between the axon and the thin layer of compact myelin. The remains of the old myelin sheath, only partially digested, was sometimes present within the Schwann cytoplasm outside the new myelin sheath. Another indication that loss of myelin and remyelination had taken place was the occurrence of very short internodal lengths in the pathological nerves. Vizoso and Young (1948) showed in the rabbit that internodal lengths were greatly reduced in peripheral nerves which had regenerated following Wallerian degeneration; Fullerton, Gilliatt, Lascelles, and Morgan-Hughes (1965) also demonstrated an increase in the number of short internodes in nerves which had remyelinated following lead and diphtheritic neuropathies.

The 'delamination' process which Cammermeyer (1956) suggested as the mechanism of demyelination in hypertrophic neuropathy probably represented various stages in remyelination.

A reduction in the number of axons in this disease was noted by Dejerine and Sottas (1893) and they considered that this loss followed the disappearance of the myelin sheath. Many of the demyelinated axons survive, however, and appear to have been remyelinated although some axons had areas of their surface which were not even invested by Schwann cell. Although these axons appeared to be morphologically normal it is not possible to say how long such naked axons would remain normal, how large an area of surface devoid of Schwann cell covering was compatible with survival of the axon or even, how long the axon would remain partially naked. This situation is probably abnormal, for even in developing nerves there is always some Schwann cell covering between the axons and the endoneurium (Cravioto, 1966). It was not possible, however, during the present observations to determine the effect of extensive Schwann cell retraction upon the axon.
This study has been mainly concerned with the identification of the cells and the structural pathology in hypertrophic neuropathy. It has shed little light upon the aetiology of the disease except that it has unequivocally placed this condition into the category of primary demyelination with the probable primary defect in the Schwann cell. This group of diseases seems to fall into two major divisions. The first are the more acute demyelinating lesions which include diphtheritic neuropathy (Meyer, 1881; Cavanagh and Jacobs, 1964), lead neuropathy (Gombault, 1880), and the segmental demyelination which occurs during the infiltration of nerves by tumour cells (Kashef and Das Gupta, 1967). In these diseases the damage to the Schwann cells is not continuous over a long period, and if the animalsurvives, remyelination takes place with the ultimate return of the myelin sheaths to normal thickness. The second group of diseases may be considered as more chronic processes where myelin breakdown is recurrent. This group includes the generalized hypertrophic neuropathy and possibly the localized form which affects only short sections of nerve (Simpson and Fowler, 1966). Thomas and Lascelles (1965) have also shown that segmental demyelination may occur in diabetic neuropathy, and in a recent communication they have also described onion-bulb whorls in the peripheral nerves in this disease (Thomas and Lascelles, 1966).

The onion-bulb whorls are by no means specific to hypertrophic neuropathy for, besides diabetes, a similar picture may be seen in neurofibromata (Sorgo, 1902; Bailey and Herrmann, 1938).

In view of these divergent conditions in which this cellular picture is encountered it is possible that the disease in the three patients presented here may have several separate causes eliciting a similar reaction from the Schwann and Remak cells. Until we know more of the genetic and external influences that control the Schwann cell and its myelin-forming functions the question of pathogenesis must remain open.

\section{SUMMARY}

Three cases of hypertrophic peripheral neuropathy are described. They differed both in their ages of onset and rates of progression of the disease; only one patient had a definite family history. However, the symptoms and histological features of the peripheral nerves were similar. Electron microscopy showed that the typical 'onion-bulb' whorls were composed of overlapping Schwann or Remak cell processes arranged in concentric layers around a central axon. The layers were separated by endoneurial collagen. The central axon was usually, but 
not always, surrounded by a layer of Schwann cytoplasm and often by a thin myelin sheath. Very few myelin sheaths of normal thickness were found, and there was evidence of active demyelination and remyelination. It is concluded that the changes of hypertrophic neuropathy should be regarded as a non-specific reaction of Schwann cells to several agencies and not as a disease process per se.

I am grateful to Dr. J. B. Cavanagh and Professor P. E. Polani for their help and advice in this paper. I would also like to thank Dr. M. J. McArdle and Dr. P. R. Evans for permission to study theil patients, and Mr. B. Oswald for his technical assistance. This work was supported by the Multiple Sclerosis Society and the Polio Fund. I am indebted to the National Spastics Society for the use of the electron microscope.

\section{REFERENCES}

Austin, J. H. (1956). Observations on the syndrome of hypertrophic neuritis. Medicine (Baltimore), 35, 187-237.

Bailey, P., and Herrmann, J. D. (1938). The rôle of the cells of Schwann in the formation of tumors of the peripheral nerves. Amer. $J$. Path., 14, 1-38.

Cammermeyer, J. (1956). Neuropathological changes in hereditary neuropathies: manifestations of the syndrome heredopathia atactica Polyneuritiformis in the presence of interstitial hypertrophic polyneuropathy. J. Neuropath. exp. Neurol., 15, 340-367.

Causey, G. (1960). The Cell of Schwann. Livingstone, Edinburgh.

Cavanagh, J. B., and Jacobs, Jean M. (1964). Some quantitative aspects of diphtheritic neuropathy. Brit. J. exp. Path., 45, 309-322.

Cravioto, H. (1965). The rôle of Schwann cells in the development of human peripheral nerves-An electron microscopic study. J. Ultrastruct. Res., 12, 634-651.

- (1966). Electron microscopy of the myelination of the human fetus. Proc. fifth int. Congr. Neuropath., Zurich, 1965, pp. 744-746. (Int. Congr. Ser. No. 100.) (Excerpta Medica, Foundation, Amsterdam.)

Dejerine, J., and Sottas, J. (1893). Sur la névrite interstitielle, hypertrophique et progressive de l'enfance. C.R. Soc. Biol. (Paris), 45, (ser. 9, 5) 63-96.

$\longrightarrow$, and André-Thomas (1906). Sur la névrite interstitielle hypertrophique et progressive de l'enfance (deuxième observation suivie d'autopsie). Nouv. Iconogr. Salpêt., 19, 477-509.

Farquhar, M. G., and Palade, G. E. (1963). Junctional complexes in various epithelia. J. Cell Biol., 17, 375-412.

Fullerton, Pamela M., Gilliatt, R. W., Lascelles, R. G., and MorganHughes, J. A. (1965). The relation between fibre diameter and internodal length in chronic neuropathy. J. Physiol. (Lond.), 178, 26P-28P.

Gamble, H. J. (1966). Further electron microscope studies of human foetal peripheral nerves. J. Anat. (Lond.), 100, 487-502.

human foetal peripheral nerves. Ibid., 99, 573-584.
- and Eames, R. A. (1964). An electron microscope study of the connective tissues of human peripheral nerve. Ibid., 98, 655-663.

Geren, B. B. (1954). The formation from the Schwann cell surface of myelin in the peripheral nerves of chick embryos. Exp. Cell Res., 7, 558-562.

Gombault, A. (1880). Contribution à l'étude anatomique de la névrite parenhcymateuse subaiguë et chronique-névrite segmentaire péri-axile. Arch. Neurol. (Paris), 1, 11-38, 177-190.

Autopsie. Arch. Méd. exp., 1, 385-415.

Kashef, R., and Das Gupta, T. K. (1967). Segmental demyelination in peripheral nerves in the presence of malignant tumours: An electron microscopic study. Br. J. Cancer, in the press.

Meyer, P. (1881). Anatomische Untersuchungen über diphtheritische Lähmung. Virchows Arch. path. Anat., 85, 181-226.

Nathaniel, E. J. H., and Pease, D. C. (1963a). Regenerative changes in rat dorsal roots following Wallerian degeneration. J. Ultrastruct. Res, 9, 533-549.

,$--(1963 b)$. Collagen and basement membrane formation by Schwann cells during nerve regeneration. Ibid., 9, 550-560.

Palade, G. E. (1952). A study of fixation for electron microscopy. J. exp. Med., 95, 285-298.

Ross, L. L. (1964). In Electron Microscopic Anatomy, edited by S. M. Kurtz, pp. 341. 367. Academic Press, New York and London.

Roussy, G., and Cornil, L. (1919). Névrite hypertrophique progressive non familiale de l'adulte. Ann. Méd., 6, 296-305.

Russell, W. R., and Garland, H. G. (1930). Progressive hypertrophic polyneuritis, with case reports. Brain, 53, 376-384.

Simpson, D. A., and Fowler, M. (1966). Two cases of localized hypertrophic neurofibrosis. J. Neurol. Neurosurg. Psychiat., 29, 80-84.

Sorgo, J. (1202). Zur Histologie und Klinik der Neurofibrome nebst Bemerkungen über das Verhalten der Patellarreflexe bei Querschnittsläsionen des Rückenmarkes im unteren Brustmarke. Virchows Arch. path. Anat., 170, 399-429.

Thomas, P. K., and Lascelles, R. G. (1965). Schwann-cell abnormalities in diabetic neuropathy. Lancet, 1, 1355-1357.

- (1966). The cellular response to nerve injury. I. The cellular outgrowth from the distal stump of transected nerve. J. Anat. (Lond.), 100, 287-303.

pathy. Quart. J. Med., 35, No. 140, 489-509. , (1967). Hypertrophic neuropathy: A light and electron microscope study. Ibid., in press.

Vizoso, A. D., and Young, J. Z. (1948). Internode length and fibre diameter in developing and regenerating nerves. J. Anat. (Lond.), 82, 110-134.

Webster, H. de F., and Spiro, D. (1960). Phase and electron microscopic studies of experimental demyelination. I. Variations in myelin sheath contour in normal guinea pig sciatic nerve. J. Neuropath. exp. Neurol., 19, 42-69.

-, Waksman, B., and Adams, R. D. (1961). Phase and electron microscopic studies of experimental demyelination. II. Schwann cell changes in guinea pig sciatic nerves during experimental diphtheritic neuritis. Ibid., 20, 5-34.

Weller, R. O. (1965). Diphtheritic neuropathy in the chicken: An electron-microscope study. J. Path. Bact., 89, 591-598.

activity in diphtheritic neuropathy and Wallerian degeneration. Brit. J. exp. Path., 47, 425-434.

Williams, P. L., and Landon, D. N. (1963). Paranodal apparatus of peripheral myelinated nerve fibres of mammals. Nature (Lond.), 198, 670-673. 